\title{
Care is needed in epidemiological research not to overgeneralise about cancer diagnosis and treatment
}

\author{
Carmen Tsang research fellow ${ }^{1}$, Alex Bottle senior lecturer ${ }^{2}$, Azeem Majeed professor of primary \\ care $^{2}$, Paul Aylin clinical reader in epidemiology and public health ${ }^{2}$
}

${ }^{1}$ London School of Hygiene and Tropical Medicine, London WC1H 9SH, UK; ${ }^{2}$ Imperial College London, London, UK

We agree with McCartney's suggestion that researchers must be cautious about how they report their findings in papers for publication and in their contacts with the media.

The limitations of secondary uses of data in research, including potential incompleteness, poor accuracy, and missing clinical data of value to research, have been well established and discussed. In our paper that McCartney cited, we showed that estimates of cancer diagnosed by emergency admission depend on the data used and the care settings from which the data were collected. ${ }^{2}$ Open access data sharing, such as the Open Exeter system, is increasingly common in healthcare and other sectors. ${ }^{45}$ One benefit of the prime minister's drive for "transparency and open data" is the potential uses of linked data in research to improve our understanding of patient pathways to care. ${ }^{5}$ For investigating the appropriateness and timing of cancer diagnoses, data sources such as hospital episode statistics, Clinical Practice Research Datalink, the health improvement network database, cancer audit data, and cancer registries can be linked to examine patients' health seeking behaviours and the interactions between patients and GPs before diagnosis.

GP activity may appropriately differ by the type of suspected cancer, the age of the patient, and presenting symptoms. We must be careful in epidemiological research not to overgeneralise about cancer diagnosis and treatment. Symptoms, disease progression, prognoses, and patient outcomes vary by cancer type. Research should further examine what information GPs and other clinicians would find most useful to support timely diagnosis of cancer and how best to incorporate these data into clinical practice. There must also be a focus on resolving preventable delays caused by the patient, clinician, and health provider.

\section{Competing interests: None declared.}

McCartney M. How many new cancers are diagnosed after emergency admission? BMJ 2013;347:f6857. (20 November.)

2 Bottle A, Tsang C, Parsons C, Majeed A, Soljak M, Aylin P. Association between patient and general practice characteristics and unplanned first-time admissions for cancer: observational study. Br J Cancer 2012;107:1213-9.

3 Tsang C, Bottle A, Majeed A, Aylin P. Cancer diagnosed by emergency admission in England: an observational study using the general practice research database. BMC Health Serv Res 2013;13:308.

4 Health and Social Care Information Centre. Value added products/services: Open Exeter-online access to the NHAIS system. 2013. http://systems.hscic.gov.uk/ssd/ prodserv/vaprodopenexe/

5 Cameron, D. Letter to cabinet ministers on transparency and open data. 2011. https:// www.gov.uk/government/news/letter-to-cabinet-ministers-on-transparency-and-open-data. 